\title{
Degradation rate of vitamin B6 on red chili pepper drying by blanching- brine-calcium pretreatment
}

\author{
Uma Fadzilia Arifin*, Mohamad Djaeni \\ Department of Chemical Engineering, Faculty of Engineering, Diponegoro University \\ Jl. Prof. Soedarto, SH, Tembalang, Semarang, 50275, Indonesia
}

Article history:

Received: 30 September 2017 / Received in revised form: 28 October 2017 / Accepted: 2 November 2017

\begin{abstract}
Drying is one of the alternatives to prevent spoilage in red chili pepper by removing moisture content. Red chili pepper (Capsicum frutescens) has complex nutrition components such as vitamins and bioactive compound. However, vitamin B6 content in chili can degrade significantly in drying process by heat. This research studied degradation rate of vitamin B6 in chili drying process under various pretreatments and temperatures. In this study, post-harvest chili before dried was pretreated by blanching, osmotic dehydration with brine, immersing in calcium chloride solution and the combination of all them. They were dried in tray dyer at various temperatures $40^{\circ} \mathrm{C}, 50^{\circ} \mathrm{C}, 60^{\circ} \mathrm{C}$ and $70^{\circ} \mathrm{C}$. Degradation of vitamin B6 content was analyzed every 2 hours by High-Performance Liquid Chromatography for 8 hours. Results showed that blanching-brine-calcium pretreatment was expected to reduce drying time and retain high content of vitamin B6 in red chili pepper. The degradation rate of vitamin B6 in chili followed second-order reaction. The degradation rate was influenced by temperature change referring to Arrhenius equation with activation energy was about $31.97 \mathrm{~kJ} / \mathrm{mol} \mathrm{K}$ and constant rate $\left(k_{0}\right)$ was 3.769 . Therefore, the vitamin B6 retention can be estimated at various pretreatments, times and temperatures. Furthermore, the favorable drying conditions can be evaluated.
\end{abstract}

Keywords: pretreatment; red chili pepper drying; degradation rate of vitamin B6

\section{Introduction}

The degradation rate is one of the mathematical models that can be used to estimate the degradation and quality behavior during food processing such as drying and storage [1]. It includes constant of degradation rate, kinetics order, and activation energy value. Red chili pepper is perishable agriculture corps due to its relatively high moisture content [2]. Post-harvest chili usually has initial moisture content around $300-400 \%$ (dry basis) [3]. Therefore, it has short shelf life.

One of post-harvest preservation alternative to prolong the shelf life is drying process by heat and mass transfer. The processes occur simultaneously to decrease the moisture $[4,5$, $6,7,8]$. However, food nutrient as important factor is sensitive to the heat load during drying [9]. One of nutrient in red chili is vitamin B6.

Vitamin B6 (pyridoxine) is one kind of vitamins that can be dissolved in water [10]. Thermal processing such as drying causes the decomposition of vitamin B6; therefore, the value of vitamin B6 in products can degrade [11]. Vitamin B6 plays an essential role in the biochemical function of the human body [12]. It can be used as a dietary supplement to prevent impaired cell-mediated, weakness, stomatitis, glossitis,

* Corresponding author

Email: umafadzilia@gmail.com peripheral neuropathies, sleeplessness, cheilosis, and immunity [12]. It makes vitamin B6 abundantly used in the food and pharmaceutical application.

The length of drying duration and operational temperature is an important factor that can be controlled to avoid degradation of vitamin B6 in red chili pepper. Previous research reported that higher temperature and longer drying time during drying result in higher degradation of vitamin B6 [11]. Therefore, pretreatment before drying is required to speed up drying rate $[13,14]$. Three main widely used drying pretreatments are blanching, osmotic dehydration and chemical pretreatment $[15,16]$. Blanching and osmotic dehydration can be applied prior to drying, which can improve quality [13]. Additionally, chemical pretreatment can significantly accelerate the drying process by removing surface resistant and consequently improve the quality of dried products [16].

Vitamin B6 as one of the important vitamins in red chili pepper was hardly investigated under drying. Besides drying rate, the degradation of vitamin B6 can be used to indicate the performance of drying method and various pretreatments. This paper studied degradation rate of vitamin B6 on red chili pepper drying under various pretreatments and temperatures. The favorable drying condition, as well as pretreatment and temperature, was evaluated in the present study to retain vitamin B6-value decrease. 


\section{Materials and Methods}

\subsection{Materials}

Fresh red chili pepper was provided in a local market in Semarang, Central Java, Indonesia. They were sorted and cleaned. Calcium chloride (food grade with purity of $94.0 \%$, Merck Germany), distilled water and sodium chloride (with purity of $97.99 \%$, UniChemCandi Indonesia) were used as pretreatment agent in chili drying. Pyridoxine standard (with purity of $99.0 \%$ p.a, Merck Germany) used for determination of vitamin B6 content in red chili pepper. Potassium acetate as a buffer and acetic acid $0.1 \%$ in methanol $70 \%$ are used as a mobile phase in HPLC. The vitamin B6 in red chili pepper was analyzed by SHIMADZU Liquid Chromatograph (LC10AT, Japan).

\subsection{Methods}

\subsubsection{Drying Procedure of Red Chili Pepper}

Red chili pepper was pretreated before the drying process. Several pretreatments applied in this research were blanching, osmotic dehydration with brine solution and chemical pretreatment with calcium chloride solution. The first sample was pretreated by blanching. The chilies were immersed in hot distilled water at $80^{\circ} \mathrm{C}-90^{\circ} \mathrm{C}$ for 3 minutes and cooled at $5^{\circ} \mathrm{C}$ water as soon as possible [13, 17]. The second sample was osmotically dehydrated by $10 \%(\mathrm{w} / \mathrm{v}) \mathrm{NaCl}$ as brine solution at $25^{\circ} \mathrm{C}$ for 30 minutes $[13,18]$. The third sample was pretreated chemically by immersing in $1 \% \mathrm{CaCl}_{2}$ [19]. The last sample was pretreated by the combination of blanchingbrine-calcium pretreatment. The with and without pretreated red chili peppers were dried using laboratory tray dryer at $40^{\circ} \mathrm{C}, 50^{\circ} \mathrm{C}, 60^{\circ} \mathrm{C}$ and $70^{\circ} \mathrm{C}$ temperatures for 8 hours, afterward. Drying was conducted at the constant air flow rate of $0.0011 \mathrm{~m}^{3} \mathrm{~s}^{-1}$. The content of vitamin $\mathrm{B} 6$ content in red chili pepper was analyzed by using HPLC method every 2 hours.

\subsubsection{HPLC Assay of Vitamin B6}

An HPLC analysis was chosen to determine vitamin B6 content. Samples around $2 \mathrm{~g}$ dissolved in $15 \mathrm{~mL}$ of $0.02 \mathrm{M}$ potassium acetate with $\mathrm{pH} 4.5$ was transferred into volumetric flasks. Then, they were sonicated for 20 minutes in Ultrasonic Cleaning Bath (Fisher Scientific Co.) at $25^{\circ} \mathrm{C}$. They were put in $25 \mathrm{ml}$ acetate buffer with the $0.02 \mathrm{M}$ concentration and $\mathrm{pH}$ 4.5. They were further centrifuged at $4300 \mathrm{rpm}$ in a Sorvall $\mathrm{RC}-5$ (type SS-34 rotor) at $25^{\circ} \mathrm{C}$ for 20 minutes. Approximately $10 \mathrm{ml}$ of the supernatant was filtered by 0.45 $\mu \mathrm{m}$ DM-450 Metricell membrane filter (Gelman Instrument Co.) prior to HPLC analysis. Thus, the sample $(50 \mu \mathrm{L})$ was ready to inject in HPLC system using column C18: 4.6x250 $\mathrm{mm}$, packing $\mathrm{L} 1$ and UV detection at $254 \mathrm{~nm}$. The vitamin B6 assaying used mobile phase $0.1 \mathrm{M}$ sodium acetate solution adjusted to $\mathrm{pH} 5.4$ with acetic acid with flow rate $1.0 \mathrm{~mL} /$ min. A small amount of methanol (up to $1 \%$ ) may be used to improve the resolution. The vitamin B6 concentration was calculated from the peak result of HPLC analyses [10, 20].

\subsubsection{Degradation Rate of Vitamin B6 Calculations}

Understanding the degradation rate of Vitamin B6 during drying is useful to estimate the concentration of vitamin B6 retained in dried red chili pepper. Parameters involved are kinetics order, constant of degradation rate $(k)$ and activation energy $\left(E_{a}\right)$ [21]. The loss of nutrient during drying can be investigated by reaction rate according to order kinetics models. In this research, to select a suitable kinetic model for describing the degradation rate of vitamin B6, the experimental data were fitted in zero, first and second kinetics order. The mathematical equation for kinetics order is shown in Table 1.

Table 1. Mathematical equation for kinetics order

\begin{tabular}{llll}
\hline \multicolumn{1}{c}{$\begin{array}{c}\text { Kinetics } \\
\text { Order }\end{array}$} & $\begin{array}{c}\text { Differential } \\
\text { Equation }\end{array}$ & Linear Regression & $\begin{array}{c}\text { Eq. } \\
\text { No }\end{array}$ \\
\hline Zero order & $-d C / d t=k$ & $C=C_{0}+k t$ & (1) \\
First order & $-d C / d t=k C$ & $\ln C=\ln C_{0}-k t$ & (2) \\
Second order & $-d C / d t=k C^{2}$ & $1 / C=1 / C_{0}+k t$ & (3) \\
\hline
\end{tabular}

In Table $1, C, C_{0}, k$ and $t$ are the concentration of vitamin B6 in current time, the concentration of the vitamin B6 at zero time, the reaction constant $\left(\right.$ time $\left.^{-1}\right)$, and time, respectively. The data of vitamin B6 concentration versus time was fitted by linear regression. The best fitting was shown by the highest value of correlation coefficient of regression $\left(R^{2}\right)$ [16]. The slope represents rate constant of vitamin B6 degradation. Vitamin B6 is sensitive to the heat load [20]. Degradation of vitamin B6 depends on temperature change. It was correlated by the Arrhenius equation.

$$
\ln k=-E_{a} / R T+k_{0}
$$

where, $k_{0}$ is a pre-exponential factor or the Arrhenius constant $\left(\right.$ time $\left.^{-1}\right), R$ is the universal gas constant $\left(8.314 \mathrm{Joule}^{\mathrm{mol}} \mathrm{mo}^{-1}\right.$ ${ }^{1}$ ), and $T$ is the absolute temperature $(\mathrm{K})$. Data of $\ln k$ versus $1 / T$ were fitted in linear regression with $-E_{a} / R$ is slope. The data were analyzed using Microsoft Excel.

\section{Results and Discussion}

\subsection{Retention of Vitamin B6 in Red Chili Pepper under Various Pretreatments}

Vitamin B6 is one of water soluble vitamin [22]. Retention of vitamin B6 in red chili pepper can decrease caused by the length of drying duration. The longer drying time can increase the degradation rate of vitamin B6. Therefore, pretreatment is required to accelerate drying rate, improve the quality, and help retain nutritional compounds $[16,23]$. In this research, there were three main pretreatments that used to help reducing drying time. They are blanching, osmotic dehydration with brine solution $(\mathrm{NaCl})$ and chemical pretreatment using calcium chloride. Blanching generally involves immersing the product in hot water. It can be used to inactivate enzymes, soften tissues and increase mass transfer during drying [13]. Osmotic pretreatment was done by immersing the product in brine as a hypertonic solution prior to drying. It can remove 
initial moisture content before drying starts, enhance mass transfer and reduce drying time [13, 24]. Furthermore, chemical pretreatment using calcium chloride according to Lewicki and Michaluk researches can be used to remove surface resistance and retain firmness in chili during drying [19]. Therefore, blanching-brine-calcium pretreatment is expected to reduce drying time and retain highly vitamin B6 in red chili pepper.

Based on vitamin B6 analysis using HPLC method, fresh red chili pepper has initial concentration of vitamin B6 around $73.7 \pm 0.507 \mu \mathrm{g} / \mathrm{g}$ dry basis of chili. Vitamin B6 content experiences degradation during drying. Various pretreatments give different results on retention of vitamin B6 in red chili pepper at current condition. Effect of various pretreatments on retention of vitamin B6 in red chili pepper drying is shown in Table 2.

Table 2. Effect of various pretreatments on retention of vitamin B6 in red chili pepper at $40^{\circ} \mathrm{C}$ during 8 hours drying

\begin{tabular}{|c|c|c|}
\hline $\begin{array}{l}\text { Pretreatment red chili } \\
\text { pepper }\end{array}$ & $\begin{array}{l}\text { Vitamin B6 amount } \\
\text { ( } \mu \mathrm{g} / \mathrm{g} \text { dry basis of } \\
\text { red chili pepper) }\end{array}$ & $\begin{array}{c}\text { The losses of } \\
\text { vitamin B6 amount } \\
(\%)\end{array}$ \\
\hline Non-pretreated dried chili & $62.6 \pm 0.727$ & 15.06 \\
\hline Blanching dried chili & $66.9 \pm 0.647$ & 9.23 \\
\hline Brine dried chili & $66.4 \pm 0.207$ & 9.91 \\
\hline Calcium dried chili & $63.3 \pm 0.847$ & 14.11 \\
\hline $\begin{array}{l}\text { Blanching-Brine-Calcium } \\
\text { dried chili }\end{array}$ & $67.5 \pm 0.347$ & 8.41 \\
\hline
\end{tabular}

Based on Table 2, chili that was pretreated by blanchingbrine-calcium pretreatment has highest retention value of vitamin B6. It revealed that expectation blanching-brinecalcium pretreatment can minimize degradation rate of vitamin B6. Meanwhile, non-pretreated chili has lowest of vitamin $\mathrm{B} 6$ retention. It means that pretreatment before drying process in red chili pepper can retain quality especially heat sensitive nutrient such as vitamin B6.

\subsection{Degradation Rate of Vitamin B6 in Blanching-Brine- Calcium Pretreatment Drying}

The degradation rate is important for estimating the thermal stability of pyridoxine according to kinetics parameters [11]. Vitamin B6 is sensitive compound by thermal process [10]. In the study, Vitamin B6 was assayed by HPLC during drying in order to estimate its degradation value. The value decrease of vitamin B6 during drying can be investigated by reaction rate according to order kinetics model. In this case, data from the blanching-brine-calcium pretreated red chili drying under various temperatures was fitted in various order kinetics by linear regression, i.e. zero, first and second order. It aims to select a suitable order kinetics model for describing the degradation rate of vitamin B6 and determining constant rate $(k)$. The result of plotting data in various kinetics orders can be seen in Table 3 .

Table 3 reveals that second order has highest $R^{2}$ at each temperature in the degradation rate of vitamin B6 in blanching-brine-calcium pretreated chili drying. The suitable fitting was showed by the highest value of correlation coefficient $\left(R^{2}\right)$ [16]. Hence, the degradation rate of vitamin B6 in blanching-brine-calcium pretreated chili drying followed second-order kinetics by linear regression. It was different from the previous studies by Evans et al., about degradation rate of vitamin B6 on the cereal toasting [20] and Gregory et al., regarding the degradation rate of vitamin B6 on casein-based liquid model food systems [25]. They assume that degradation rate of vitamin B6 (pyridoxine) can be described by first-order kinetics. It was possible because the degradation rate of vitamin B6 in various materials was different depending on matrix structure and processing conditions. In this case, the blanching-brine-calcium pretreatment could be a factor why second-order was suitable for degradation rate of vitamin B6 in chili drying.

Table 3. Result of plotting data vitamin B6 in blanching-brine-calcium pretreated chili drying under various temperatures for 8 hours on various kinetics orders

\begin{tabular}{cccc}
\hline Kinetics order $n$ & Temperature $\left({ }^{\circ} \mathrm{C}\right)$ & $K$ & $R^{2}$ \\
\hline 40 & 0.8133 & 0.9895 \\
0 & 50 & 1.3383 & 0.9865 \\
& 60 & 1.7833 & 0.9515 \\
& 70 & 2.3833 & 0.9635 \\
& 40 & 0.0115 & 0.9923 \\
& 50 & 0.0193 & 0.9900 \\
& 60 & 0.0263 & 0.9666 \\
& 70 & 0.0363 & 0.9801 \\
& 40 & 0.0002 & 0.9947 \\
& 50 & 0.0003 & 0.9916 \\
& 60 & 0.0004 & 0.9787 \\
& 70 & 0.0006 & 0.9906 \\
\hline
\end{tabular}

That fact that vitamin B6 can be easily degraded in thermal process was proved in this research. Fig. 1 shows plotting data in second-order kinetics by linear regression. It informs us that the degradation rate of vitamin B6 depended on temperature and drying time. The higher temperature and longer drying time caused the increasing degradation rate of vitamin B6 in red chili pepper. Degradation rate can be also observed according to the constant value of degradation rate (k). The constant of degradation rate $(\mathrm{k})$ was represented by slope value in Fig. 1.

Based on Table 1 and Fig. 1, we can conclude that the higher temperature results in the higher constant value of degradation rate. It showed that the higher temperature causes the lower vitamin B6 retention or the faster degradation rate of vitamin B6 at the same time. Therefore, known constant of vitamin B6 degradation rate during drying process was required to predict retention of vitamin $\mathrm{B} 6$ at the current time, various temperatures and various pretreatments. So, the favorable drying conditions can be evaluated.

\subsection{Temperature Dependence of Vitamin B6 Degradation}

Degradation kinetics of vitamin B6 includes the reaction rate as a function of temperature. The dependence temperature for degradation rate of vitamin B6 is important to design the 
best operational condition for drying red chili pepper to obtain the highest vitamin B6 retention. Hence, it is necessary to study the effect of various temperatures on degradation rate of vitamin B6. Many studies have been carried out to calculate the degradation rate of vitamin at elevated temperatures [21]. Degradation rate of vitamin B6 was influenced by temperature change referring to Arrhenius equation as depicted in Fig. 2.

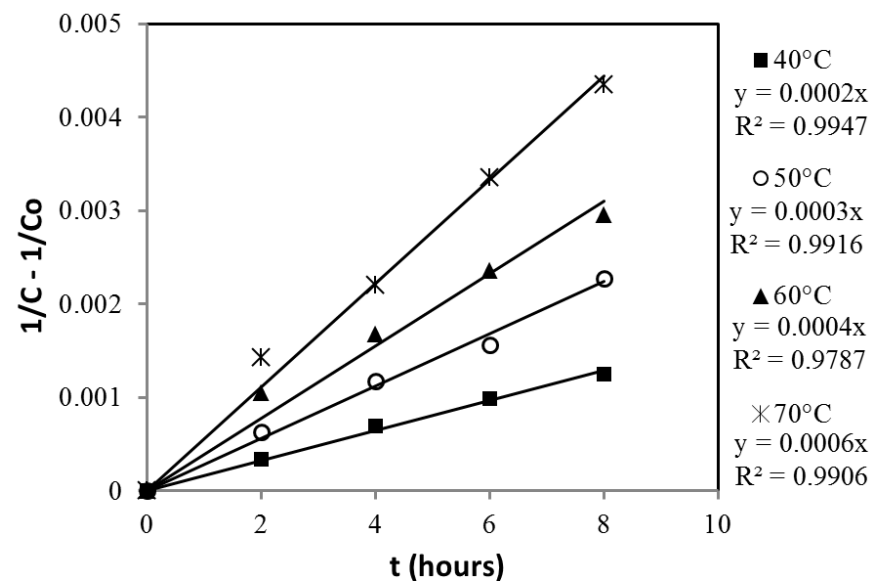

Fig. 1. Second-order kinetics of degradation vitamin B6 in blanching-brinecalcium pretreatment chili drying under various temperatures

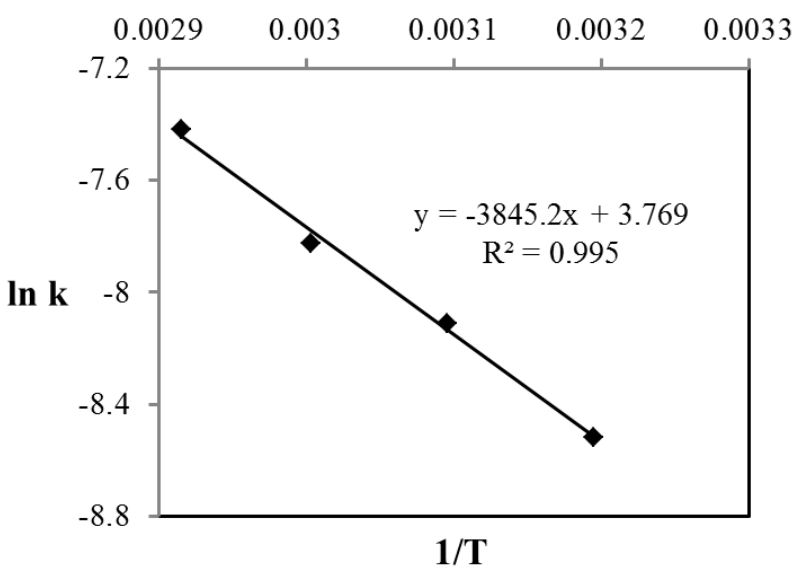

Fig. 2. Arrhenius correlation degradation rate of vitamin B6

Data fitted in linear regression on Fig. 2, can be used to express vitamin B6 degradation for any temperatures. Based on arrhenius equation in Eq. 4, we can calculate energy activation from slope value. The activation energy $\left(E_{a}\right)$ of vitamin B6 degradation in chili drying by blanching-brinecalcium pretreatment was found to be $31.97 \mathrm{~kJ} / \mathrm{mol}$. In addition, pre-exponential factor or Arrhenius constant $\left(k_{0}\right)$ represented by intercept was about 3.769. The constant value of vitamin B6 degradation rate at other temperature can be determined based on the value of $E_{a}$ and $k_{0}$, as formulated by.

$$
\ln k=-31.97 / R T+3.769
$$

Therefore, the vitamin B6 retention can be estimated at various pretreatment, times and temperatures. It is possible to design the best operational condition for drying red chili pepper to obtain the highest vitamin B6 retention.

\section{Conclusion}

Vitamin B6 is a water-soluble vitamin that is sensitive by heat load during drying process and duration of drying. Pretreatment was required to speed up drying rate. It can retain the quality of dried product such as vitamin B6. Fresh red chili pepper has initial concentration vitamin B6 that was around $73.7 \pm 0.507 \mu \mathrm{g} / \mathrm{g}$ dry basis of chili. Blanching-brinecalcium pretreatment has the highest amount of vitamin B6 retention. The degradation rate of vitamin B6 in drying red chili pepper with blanching-brine-calcium pretreatment was categorized as second-order reaction with activation energy was about $31.97 \mathrm{~kJ} / \mathrm{mol} \mathrm{K}$ and $k_{0}$ was 3.769 . Therefore, the vitamin $\mathrm{B} 6$ retention can be estimated at various pretreatments, times and temperatures. It is possible to design the favorable operational condition for drying red chili pepper to obtain the highest vitamin B6 retention.

\section{References}

1. P. N. Rekha, S. Singhal, and A. B. Pandit, A study on degradation kinetics of thiamine in red gram splits ( Cajanus cajan L.), Food Chem. 85 (2004) 591-598.

2. N. C. Wade, S. S. Wane, and S. M. Kshirsagar, Comparative study of drying characteristics in chillies, Ind. J. Sci. Res. Tech 2 (2014) 105111.

3. S. Charmongkolpradit, K. Triratanasirichai, and N. Srihajong, Drying characteristics of chili using continuous fluidized-bed dryer, Am. J. Appl. Sci. 7 (2010) 1300-1304.

4. E. O. M. Akoy, Experimental characterization and modeling of thinlayer drying of mango slices, Int. Food Res. J. 21 (2014) 1911-1917.

5. I. Alibas, Mathematical modeling of microwave dried celery leaves and determination of the effective moisture diffusivities and activation energy,Food Sci. Technol. 34 (2014) 394-401.

6. M. Torki-Harchegani, D. Ghanbarian, and M. Sadeghi, Estimation of whole lemon mass transfer parameters during hot air drying using different modelling methods, Heat Mass Transf. (2014).

7. M. Beigi, Energy efficiency and moisture diffusivity of apple slices during convective drying, Food Sci. Technol. 36 (2016) 145-150.

8. M. Djaeni, U. F. Arifin, and S. B. Sasongko, Physical-Chemical Quality of Onion Analyzed Under Drying Temperature, International Conference on Chemistry Chemical Process and Engineering 2016, Yogyakarta, Indonesia, 2017, pp. 1-5.

9. M. Djaeni, C. J. van Asselt, P. V. Bartels, J. P. M. Sanders, G. van Straten, and A. J. van Boxtel, Low temperature drying with air dehumidified by zeolite for food products: energy efficiency aspect analysis, Int. J. Food Eng. 7 (2011) 1-25.

10. H. K. Trang, Development of HPLC methods for the determination of water-soluble vitamins in pharmaceuticals and fortified food products, Thesis, Clemson University, 2013.

11. M. Juhász, S. Takahashi, Y. Kitahara, and T. Fujii, Thermal decomposition of pyridoxine: an evolved gas analysis-ion attachment mass spectrometry study, Rapid Commun. Mass Spectrom. 26 (2012) 759-764.

12. G. F. Combs, The Vitamins: fundamental aspects in nutrition and health. California, USA: Elsevier Academic Press, 2008.

13. P. T. Akonor and C. Tortoe, Effect of blanching and osmotic pretreatment on drying kinetics, shrinkage and rehydration of chayote (sechium edule) during convective drying, Br. J. Appl. Sci. Technol. 4 
(2014) 1215-1229

14. H. Tavakolipour and M. Mokhtarian, Drying of Chili Pepper in Different Conditions, Proceedings of TheIRES 4th International Confererence, Kuala Lumpur, Malaysia, 2015, pp. 71-74.

15. T. Y. Tunde-Akintunde, Effect of pretreatment on drying time and quality of chilli pepper, J. Food Process. Preserv. 34 (2010) 595-608.

16. E. Abano, E, H. Ma, W. Qu, and E. Teye, Modeling pre-treatments effect on drying kinetics of garlic (Allium sativum L.) slices in a convective hot air dryer, African J. Food Sci. 5 (2011) 425-435.

17. N. Toontom, W. Posri, S. Lertsiri, and M. Meenune, Effect of drying methods on Thai dried chilli's hotness and pungent odour characteristics and consumer liking, Int. Food Res. J. 23 (2016) 289299.

18. W. Phomkong, S. Soponronnarit, and P. Thammarutwasik, Chemical pretreatments affecting drying characteristics of chilli (cv. Huarou Yon), Dry. Technol. 28 (2010) 1466-1476.

19. P. P. Lewicki and E. Michaluk, Drying of tomato pretreated with calcium, Dry. Technol. An Int. J. 22 (2004) 1813-1827.

20. S. R. Evans, J. F. Gregory, and J. R. Kirk, Thermal degradation kinetics of pyridoxine hydrochloride in dehydrated model food systems, J. Food Sci. 46 (1981) 555-563.

21. V. B. Vikram, M. N. Ramesh, and S. G. Prapulla, Thermal degradation kinetics of nutrients in orange juice heated by electromagnetic and conventional methods, J. Food Eng. 69 (2005) 31-40.

22. H. Hellmann and S. Mooney, Vitamin B6: A molecule for human health?, Molecules 15 (2010) 442-459.

23. I. Doymaz, Pretreatment effect on sun drying of mulberry fruits ( Morus alba L.), J. Food Eng. 65 (2004) 205-209.

24. F. A. N. Fernandes, S. Rodrigues, O. C. P. Gaspareto, and E. L. Oliveira, Optimization of osmotic dehydration of papaya followed by air-drying, Food Res. Int. 39 (2006) 492-498.

25. J. F. Gregory and M. E. Hiner, Thermal stability of vitamin B6 compounds in liquid model food systems, J. Food Sci. 48 (1983) 13231339. 